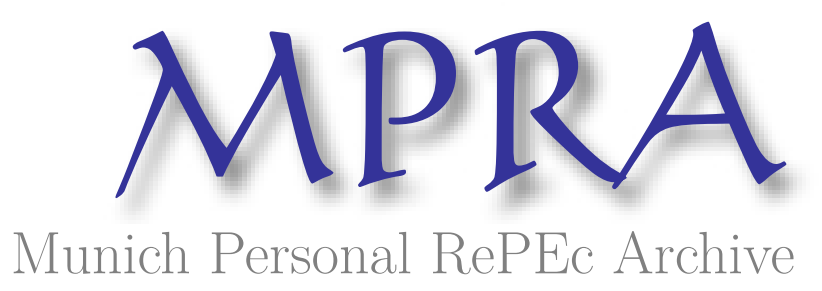

\title{
Theoretically proposed policy instrument to resolve the negative effect of inflation flow into a positive macroeconomic growth: the case of Sierra Leone economy
}

Tweneboah Senzu, Emmanuel

Central Bank of Sierra Leone, Njala University, School of Social Science, Frederic Bastiat Institute, Africa

1 April 2020

Online at https://mpra.ub.uni-muenchen.de/99402/

MPRA Paper No. 99402, posted 08 Apr 2020 11:26 UTC 
Theoretically proposed policy instrument to resolve the negative effect of inflation flow into a positive macroeconomic growth: the case of Sierra Leone economy

\author{
Emmanuel TWENEBOAH SENZU \\ Professor of Economics and Investment Banking \\ School of Social Science, Njala University of Sierra Leone. \\ Central Bank of Sierra Leone
}

\begin{abstract}
The paper empirically examines the predictive factor of the inflation rate observed to be the vector force of macroeconomic growth decline or rise in the Sierra Leone economy. Thereby adopting a statistical tool of an exogenous univariate auto-regression integrated moving average to build a forecasting model between the open-market-exchange rate and the inflation rate to establish the degree of correlation effect as a basis to theoretically prescribe a policy instrument, a means to maximize economic benefit for sustainable macroeconomic growth. This leads to an established finding that an average price shift of $+/-0.032$ of the leone currency price with the US dollar at the open market will always cause a percentage point change of inflation to the endogenous economy when all other factors remain constant.
\end{abstract}

Keywords: Inflation, Exchange rate, policy instrument, regression models, monetary policy JEL Codes: E5, E17, E52, E58

*The information provided by the author is provided in good faith, however, as the Central Bank, we make no warranty of any kind, express or implied regarding the adequacy, and reliability. Therefore no circumstance the Central Bank will have any liability for any loss or damage of any kind incurred or reliance on any information Email: tsenzu@cctu.edu.gh $\mid$ tsenzu@njala.edu.sl | tsenzu@fbiresearchedu.org 


\section{A. INTRODUCTION AND BACKGROUND}

The Currency called 'Leone' with the ISO code as 4217 and the symbol SLL at the Global Financial market became an official currency of Sierra Leone in 1964 after the government decided to replace the British West African pound $[\mathrm{BWF}(\mathrm{P})]$ with the Leone at an exchange rate of 1:2 an implication that every Le 2 was equivalent to $\mathrm{BWF}(\mathrm{P}) 1$. Leading to the issuance of the Leone coins of Le 1, Le 5, Le 10 and Le 20, which carried the face of Sir Milton Augustus Strieby Margai, who served as a head of government from 1954 to 1964 . It was historically observed that the rate of inflation from 1964 up to 1995 was extremely high and seem to have attained some level of marginal escalation beginning from the year 1996 onwards. This permitted the government to further issue new leone coins for Le 10, 20, 50 and 100. Around 2014, Le 500 coin was finally introduced. In 2010, the official Central Bank of Sierra Leone on behalf of the government, introduced a new banknote ranging from Le1,000, Le 2,000, Le5,000 and Le 10,000 which is in circulation for economic transaction up to date. Currently, cent rated over Leon is 1:100 as its monetary unit. It is further observed, throughout the history of Sierra Leone after independence in 1961, it only from 1996 onwards the country could boast of major inflation stable trend of endogenous character within the scope of scientific analysis and forecast. Which worth diagnostic study and innovative proactive policy recommendation. Analyzing from the researcher observation and point of view, extensive scholarly writings of the financial-economic market of Sierra Leone started from the year 2000s. Prior to this date, most scholarly writings did focus on the community mining programs and the trade transactions across the Sierra Leone economy, analyzing it positive and negative impact. For instance, the submission of Ravichandran(2011), analyzed the major causes of economic disorder and high corruption rate which lies within the government. And concluded by elaborating on the oppression and marginalization of individuals, both within and outside of tribal groups deepening the poverty 
rate in Sierra Leone. Gottschalk, et.al, (2008) argued in favour of my earlier claim of lack of empirical data of Sierra Leone economic market before the 2000s. And reported, data limitations arise because of civil conflict introducing severe structural breaks in the data, restricting the analysis to the post-conflict period as well as lack of statistical capacity, especially regarding the collection of real sector data.

Beginning from the period of 2000s, Kovanen (2006) conducted a cross-section and time-series regression to establish an understanding of the inflation dynamics in Sierra Leone. His findings conclude the market price changes are frequent due to uncertainty about inflation, as well as low value-added content to domestic products. His final remarks stated, the timing of repricing tends to be State-dependent unlike developed economies, which tends to be predetermined. And suggested the reduction of monetary surprises and supply constraints would help reduces the fraction of items being repriced and the frequency of repricing, thus reducing the level and volatility of inflation. Despite (Gottschalk et.al, 2008) submission on the significant contributing factor of the inflation escalate in Sierra Leone beyond the Central Bank's ability, which was defined as Institutional weaknesses and fiscal needs, the major key factor was the Central Bank capital positioning was very weak with a portfolio of treasury bills and treasury bearer bond, very insufficient to conduct meaningful open market operations. There was also a situation whereby the fiscal policy stance conflicting most at times with the Central Bank reserve money target, with the Central Bank taken mostly passive monetary policy stance, which results in a frequent overshoot of it an intermediate monetary target, a key contributive factor to persistently high inflation. (Gottschalk, Kalonji, and Miyajima, 2008) argued, the fiscal expansion complicated the conduct of monetary policy because of deficit financing through foreign grants and borrowing from the Central Bank to increase the money supply in the absence of 
Sterilization. Which the Central Bank had an alternative approach to resolve this problem as a significant contribution to inflation by engaging in open market operations to sterilize the increase of the money supply through the engagement of the sales of foreign exchange. But the Central Bank initially lacked the will to do so because of it primary objective was to build a comfortable reserve cover and such engagement in open sales of foreign exchange could lead to undesirable exchange rate fluctuations. Moving forward as a proactive Central Bank to resolve some of the inflationary causes within monetary policy stance, the first-ever memorandum of understanding was entered between the Central Bank and the Ministry of Finance in October 2006 to help in the conversion of part of the non-interest bearing, non-negotiable government paper into treasury bills to replenish the prescribed minimum paid-up capital of the Central Bank as a well-developed instrument to conduct open market operations. Fast forward to 2019, (Jackson, Tamuke and Jabbie, 2019) argued through their paper that, the major key causes of inflation in Sierra Leone economy is weak real sector activities, excessive fiscal expenditure by government, imbalance of payment activities and expansionary monetary policy and recommend that real sector productivity is required to reduce the extent of import commodity. Then further recommends the adoption of interest rate payment for foreign account holders in Sierra Leone as well as digital innovation to minimize the high level of cash transactions in circulation. 


\section{B. THEORITICAL AND EMPIRICAL REVIEW}

Inflation in the definition of economic taxonomy implies sustained increase in the general price level of goods and services in an economy over a period of time. In respect to the ex-post-facto observation, after the independence era of countries in Sub-Saharan Africa as the focal study of the researcher, it became evidence, most of these countries are struggling with the capping down their real inflation rate below 5\% averagely in annual basis and sustain it, with their Central Banks helpless to achieve the target for a desired economic growth. Which has become the driving theoretical interest of this paper to propose a structured economic environment friendly to the unpredictable marginal rise of inflation rate in such fragile economies, instead of the current enemy adopted approach of Central Banks to Inflation through the assumptive monetary policy capping. The paper chooses to explore contrarily view of modern theoretical bias of inflation rate against economic growth. In the desire to critically diagnosed the economic structure of a State in this instance Sierra Leone's economy, whereby a certain high rate of inflation is permissible and desirable to the health of a fragile economy of this nature. (Carvalho et.al, 2017) in their theoretical exposition, deduced inflation is inversely correlated with the level of the technological content of the economy, human capital, and cyclical unemployment. And concluded, the degree of inflation persistence was directly related to terms of trade growth, with an observation that there were an inverse and low correlation between inflation persistence and economic development. Bruno and Easterly (1998), empirical findings suggested economic growth and inflation are negatively related. Johnson (1967) argued, there was no conclusive empirical evidence for either a positive or a negative association of inflation to economic growth. (Wai, 1959: Bhatia, 1960: Dorrance 1963, 1966) None of this hotbed inflationist at the IMF then, with series of studies in the IMF papers around the 1960s found little evidence of damage from 
inflation to an economy. (Pazos 1972; Galbis 1979) both submitted findings around the 1970s of Latin America with a high rate of inflation then, the evidence of inflationary damage was ambiguous. Fischer (1993) found negative associations between inflation and economic growth in a pooled cross-section, time-series regression for a large set of countries. Studies from (De Gregorio, 1992, 1993: Barro,1995) have similar findings. (Levine and Zervos,1993) showed that the cross-section correlation between inflation and growth was a rare occasion. And if one could find it at all will depend on a couple of extreme inflation. Despite the outlined empirical argument of the negative inflation rate effect on economic growth, there is still a mainstream entrenched theoretical proposition of inflation's negative influence on economic growth. As part of the paper observation study among the trading industry of the Sierra Leone economy, deduce that, the high inflation economy is significantly a contributive factor to it high importation trading economy as confirmed by the study of Jackson et,al, (2019). Out of the one hundred and fifty (150) trade business owners engaged with one hundred and twenty-four (124), who expressed the desire to avail themselves as respondents to the researcher, on the key challenges facing their trade business, it became evidenced with $95 \%$ suggesting that it was profitable to engage in importation business in Sierra Leone than exportation. And the reason was that the commercial market is in price competition domestically and to be able to survive and sustain the business with the expectation of reasonable profit in such an environment, then the best option was to engage in importation business. Appreciating an extensive theoretical submission and corresponding empirical data that suggest conclusively the havoc, which inflation causes to sound economic performance against other inflationist economists who argue for the positive impact of inflation to an economy, the paper referenced the study of Ashraf et.al (2013) using an agent-based computational approach to show how inflation above 3\% worsen macroeconomic 
performance by disrupting the mechanism of exchange in a decentralized market economy with a theoretical argument on why cross-country regressions mail fails to detect a significant negative effect of trend inflation on output even when such an effect exists in reality. This paper strictly focuses it theoretical and empirical argument not to join the 'for' or 'against' of such a century debate on inflation and macroeconomic performance in the examination of the Sierra Leone economy but to argue on a sound policy structure to exploit the unseen benefit of inflation relating to the macroeconomic dynamics of Sierra Leone on the principles of Bastiat (18011850), as it states every economic action as in policy function, just like two faces of a coin, has a seen effect and unseen effect either in a short term or a long term. This also suggest a beneficial economic policy of the short term does have a long term negative effect as an unseen phase of such decision and corresponding action. Hence the relevance of establishing a probable trade-off between the benefit and the damages of both short term and long term of every economic activity is a hallmark that defined a quality policy instrument required by policy markers of developing economies. Hence appreciating the relevant reasons causing the fiscal policy stance of Sierra Leone economy to be mostly conflicting with the sound monetary policy positioning, then the role of this paper is a proponent in favour of marginal escalation of inflation rate becoming a friend or holding a positive effect to the macroeconomic performance than treating it as an enemy in the macroeconomic aggregate analysis of the same studied economy. The paper will examine empirically the leading causal factors of the Inflation rate of SL-economy, the extent of correlation effect and the kind of relationship existing between these variables as a basis to propose a policy framework and theoretical economic re-structuring to instruct economic development programs. 


\section{METHODOLOGY AND EMPIRICAL ANALYSIS}

The first choice of the method adopted by the researcher is 'process tracing' as submitted in the study of Beach(2017) as a method for tracing causal mechanisms using detailed, within-case empirical analysis of how a causal process plays out in an actual case. (Evera, 1997) argued, process tracing is the cause-effect link that connects independent variables and outcome unwrapped and divided into smaller steps; then the investigator looks for observable evidence of each step. Therefore an effort was made by the researcher to trace the causal flow effect on inflation in SL-economy, with the outcome of structural tracing model below labeled as Fig.D1

Fig. D1.

Inflation rate causal flow

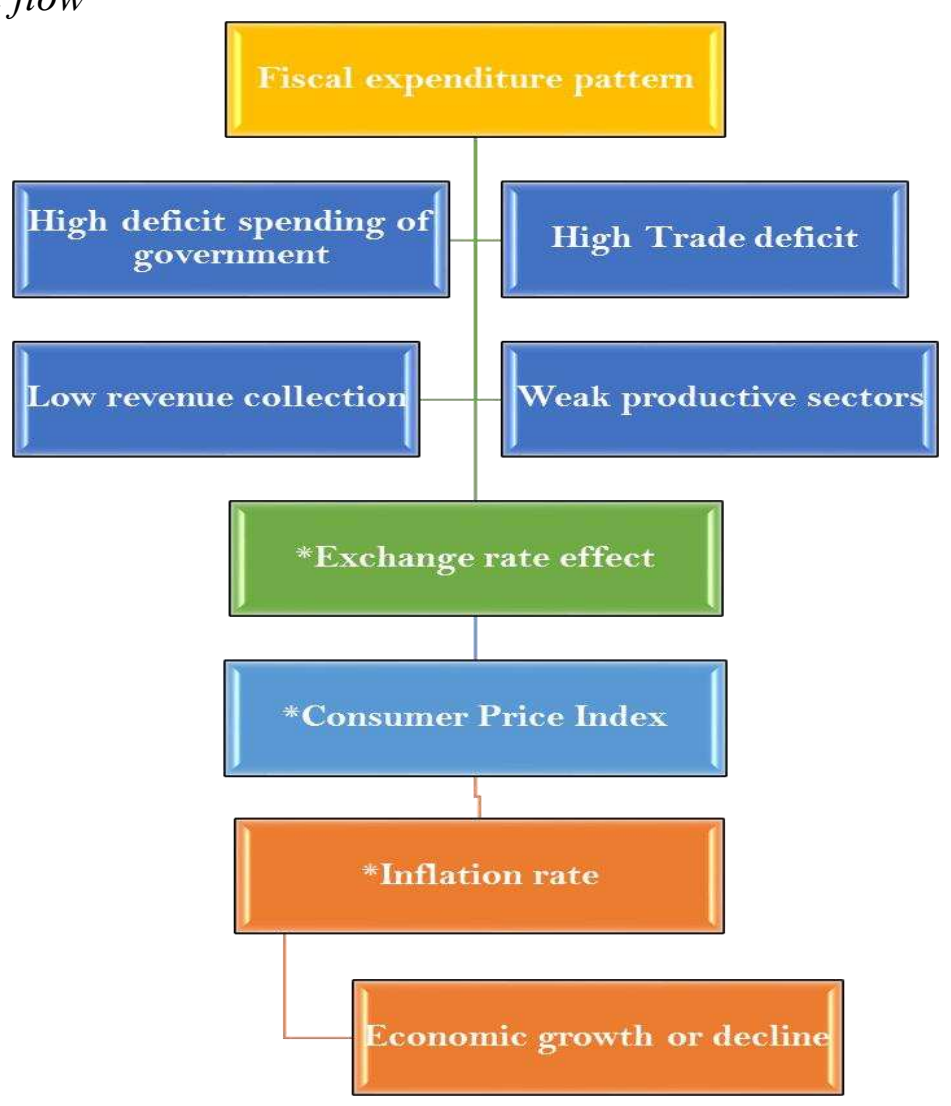

E.T. Senzu (2020) 
After the 'process tracing' to establish the actual causal factors of Inflation in the macroeconomy of Sierra Leone, which to some extent contradict some of the findings of Jackson et.al (2019) causal factors of inflation in Sierra Leone economy, it was relevant to rely on secondary data collection for the following variables as in Inflation rate, Exchange rate and Consumer price index from the credible institution like the Sierra Leone Statistical service, Central Bank and World Bank to conduct the test to examine the extent of correlation among the independents and dependent variable as well determine the statistical relation within the variables relying on time series data from 2010 to 2019 to draw inferences for theoretical deductions and propositions. Appreciating the conceptual positioning of the paper, the researcher opted to rely on the exchange rate and the open market price of the Leone currency with the US-dollar, which is further used as the Central Bank external reserve currency to represent the data-point of (EXR). The next source of secondary data from Sierra Leone Statistical service computed for the consumer price index was relied upon as a data point for (CPI). Why the averagely computed inflation rate of Sierra Leone by the World Bank was also used for the correlation analysis. The study focusing on data among the three variables from 2010 to 2019 as a choice to avoid structural data breaks across the variables. Tabled as D2, expressed data used for $|\mathrm{EXR}|$.

Table D2 [USD/SLL] |EXR|

\begin{tabular}{|l|l|l|l|}
\hline Year & Highest Price & Lowest Price & Average Price \\
\hline 2019 & 9487.10 & 7039.36 & 8002.98 \\
\hline 2018 & 8390.29 & 6304.77 & 7712.38 \\
\hline 2017 & 7662.46 & 5472.60 & 7474.56 \\
\hline 2016 & 5653.14 & 3928.39 & 4822.84 \\
\hline 2015 & 4498.77 & 3443.18 & 4146.42 \\
\hline 2014 & 4391.30 & 4219.03 & 4339.69 \\
\hline
\end{tabular}




\begin{tabular}{|l|l|l|l|}
\hline 2013 & 4355.99 & 4272.28 & 4323.40 \\
\hline 2012 & 4453.75 & 4310.86 & 4360.27 \\
\hline 2011 & 4418.87 & 3101.74 & 3689.47 \\
\hline 2010 & 4192.97 & 0.00 & 3085.69 \\
\hline
\end{tabular}

E.T.Senzu (2020)

Fig.D/2



(Senzu, 2020)

Even though there are high and low price data-point available per table D2; the researcher relied on the average data point assumed to express accurately the vector direction of the exchange rate annually, which is graphically plotted above as fig.D/2. The researcher further outsourced secondary data reports of the Consumer Price Index from the Sierra Leone Statistical Agency and computed for the average Consumer price index below. The results were tabled, as a report from 2010 to 2019 in the Sierra Leone economy and established the average, across the monthly data for the 10 years period. Table D3 with a label $\mid \mathrm{CPI}]$ as detailed below; 
Table D3.

\begin{tabular}{lccccccccccc} 
Years/Months & $\mathbf{2 0 1 0}$ & $\mathbf{2 0 1 1}$ & $\mathbf{2 0 1 2}$ & $\mathbf{2 0 1 3}$ & $\mathbf{2 0 1 4}$ & $\mathbf{2 0 1 5}$ & $\mathbf{2 0 1 6}$ & $\mathbf{2 0 1 7}$ & $\mathbf{2 0 1 8}$ & $\mathbf{2 0 1 9}$ \\
January & 14.16 & 18.48 & 16.24 & 11.32 & 8.09 & 8.64 & 9.83 & 18.66 & 14.69 & 14.35 \\
February & 17.22 & 17.48 & 15.82 & 10.63 & 7.58 & 8.26 & 9.24 & 19.82 & 14.40 & 14.08 \\
March & 17.85 & 18.07 & 16.37 & 10.89 & 7.49 & 8.29 & 9.27 & 20.22 & 14.91 & 14.77 \\
April & 18.42 & 18.32 & 16.42 & 11.16 & 7.35 & 8.51 & 9.50 & 19.20 & 15.14 & 16.56 \\
May & 17.85 & 20.83 & 14.86 & 10.28 & 7.47 & 8.54 & 10.08 & 18.91 & 16.02 & 14.97 \\
June & 18.11 & 19.78 & 14.07 & 10.14 & 7.79 & 8.67 & 10.70 & 19.41 & 16.57 & 14.65 \\
July & 18.21 & 20.93 & 13.55 & 9.52 & 7.86 & 8.69 & 10.94 & 18.56 & 17.71 & 14.89 \\
August & 18.35 & 19.53 & 12.51 & 9.34 & 8.78 & 8.88 & 11.35 & 18.01 & 18.22 & 15.43 \\
September & 18.51 & 16.98 & 11.41 & 9.07 & 8.85 & 9.31 & 11.68 & 17.83 & 19.23 & 15.16 \\
October & 17.63 & 17.01 & 11.72 & 8.93 & 8.91 & 9.66 & 12.56 & 16.86 & 19.29 & 15.85 \\
November & 18.37 & 18.07 & 12.17 & 8.71 & 9.34 & 9.98 & 15.26 & 16.26 & 18.14 & 13.09 \\
December & 18.40 & 16.91 & 11.86 & 8.53 & 9.84 & 10.07 & 17.41 & 15.33 & 17.46 & 13.89 \\
\hline AVERAGE & 17.76 & $\mathbf{1 8 . 5 3}$ & $\mathbf{1 3 . 9 2}$ & $\mathbf{9 . 8 8}$ & $\mathbf{8 . 2 8}$ & $\mathbf{8 . 9 6}$ & $\mathbf{1 1 . 4 9}$ & $\mathbf{1 8 . 2 6}$ & $\mathbf{1 6 . 8 2}$ & $\mathbf{1 4 . 8 1}$ \\
\hline & & & & & & & E. T.Senzu(2020) Computed ACPI data
\end{tabular}


Fig.D/3

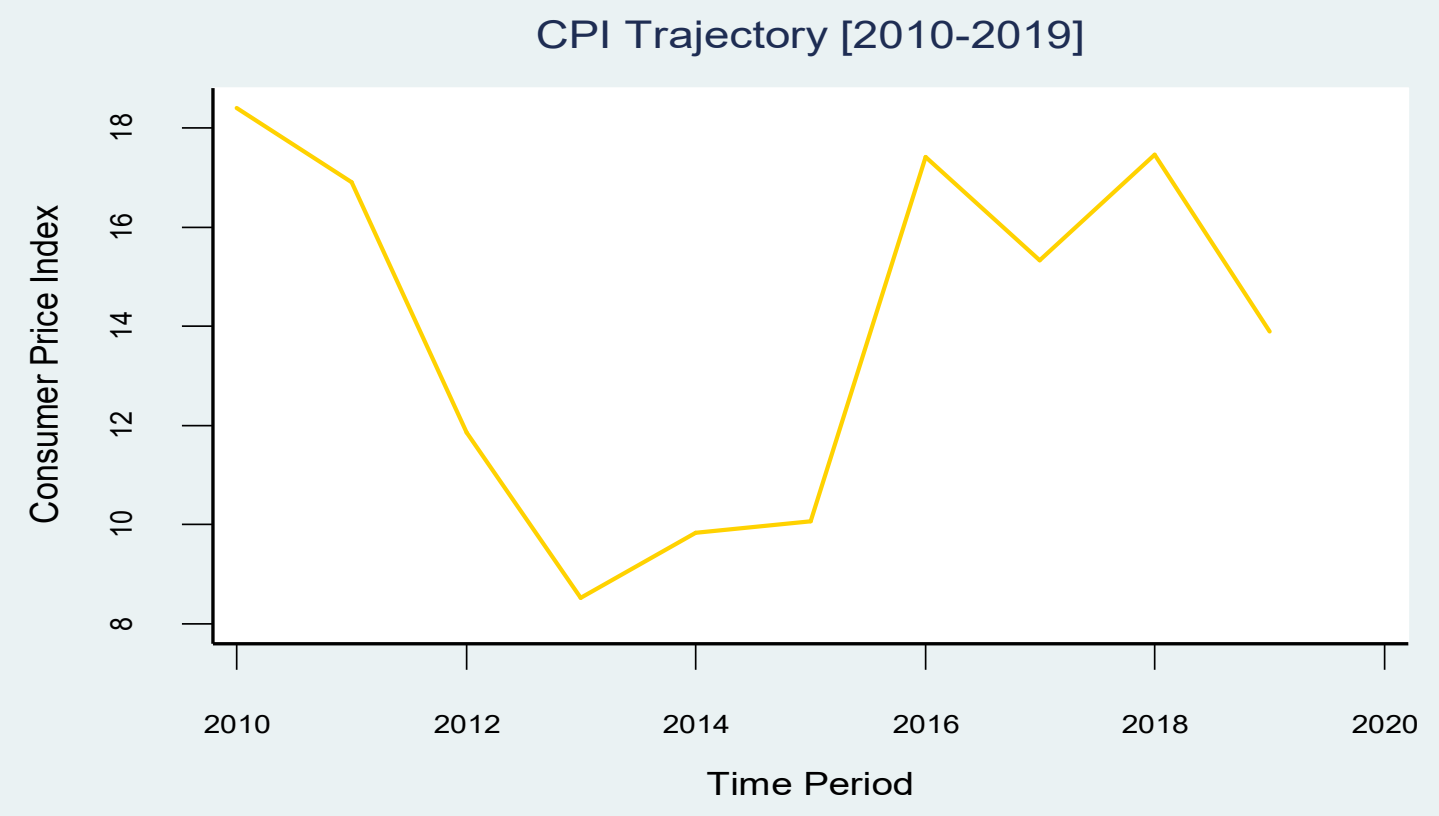

E.T.Senzu (2020)

The graph above indicates the trend of consumer price index within the Sierra Leone economy from 2010 to 2019. This suggests prices of consumer goods were very high in the early years up to 2010 and 2011 and began to decline in the latter part of 2011 up to 2014 and started rising again up to 2017, with the current situation suggesting a trend of declining. In the 'processtracing' observation, the researcher realized, there are both endogenous and exogenous factors that have a probable influence on inflation. However, the endogenous studied effects depending on how it was traced into the economy and its link to exogenous factors were noted to be statistically insignificant compared to the exogenous effect triggered mostly through the open exchange market rate using the Leone currency and the US dollars as the major medium. As a result, an effort was made to examine the extent of correlation between the exchange rate effect and inflation of SL-economy to give the basis to design a forecasting model between this two 
variables as an inferential for a theoretical proposition of policy instrument for monetary decisions, operating in the range of either high exchange rate values or low exchange rate values as an option for planning towards a progressive macroeconomic growth.

In other to establish the relation and the extent of the correlation effect among these two variables within 10years period from 2010 to 2019, a time series exogenous regression model was designed as below;

$$
Y_{t}=\mu+\beta_{1} X_{t}+\varepsilon_{t \ldots \ldots \ldots m \ldots} E q .1
$$

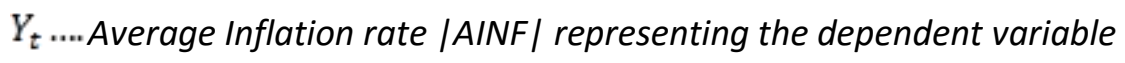

$\mu \ldots \ldots$..... Residual of the regression

$\beta_{1} \ldots \ldots . . .$. First coefficient

$X_{t} \ldots \ldots$. Average exchange rate $\left(\frac{U S D}{S L L}\right)|A E X R|$ representing a independent variable within the equation $\varepsilon_{t \ldots \ldots}$ Regressional error

$\varepsilon_{t} \ldots \ldots$ the error term from autocorrelation in error

$$
|A I N F|_{t}=\mu+\beta_{1}|A E X R|_{t}+\varepsilon_{t \ldots \ldots \ldots} E q .1-2
$$

Auto-correlation in regression model: the model was designed in a univariate series because it was observed that the $|\mathrm{ACPI}|$ and $|\mathrm{AEXER}|$ as chosen independent variables for multivariate modeling was experiencing the significant effect of multicollinearity, which the computed data will be submitted for empirical evidence at the subsequent page, hence the researcher has to rely on $|\mathrm{AEXR}|$ to represent both effects as the best statistical option for the development of the univariate regression model as below 


$$
|\operatorname{AINF}(p)|_{t}=\mu+\beta_{p} \sum_{i=(t-p)}^{n=p}|A E X R|+\varepsilon_{t} \ldots \ldots \ldots . . . . E q .3
$$

Auto-correlation in error model:

$$
|\varepsilon(q)|_{t}=\theta_{1} \varepsilon_{t-q}+\varepsilon_{t} \ldots \ldots \ldots \ldots . . . . . .4
$$

Finally, inflation data was outsourced from the World Bank inflation report of Sierra Leone within the same time frame (2010-2019), which is tabled as 'D4'.

\begin{tabular}{|l|r|r|r|r|r|r|r|r|r|r|}
\hline & & & & & & & & & & \\
\hline YEARS & 2010 & 2011 & 2012 & 2013 & 2014 & 2015 & 2016 & 2017 & 2018 & 2019 \\
\hline & & & & & & & & & & \\
INFL. REPORT \% & 7.19 & 6.79 & 6.59 & 5.52 & 4.65 & 6.69 & 10.88 & 18.22 & 16.86 & 13.63 \\
\hline
\end{tabular}

Senzu(2020) World Bank Inflation report of SL

Understanding the sensitivity nature of the variables, which the researcher was dealing with as outlined below as

\section{Average Exchange rate $|\mathrm{AEXR}|$}

2. Average Consumer Price Index |ACPI| both as independent variables and

3. Average Inflation rate $\mid \mathrm{AINF}$. $\mid$ as dependent variable. His next effort was to obtain stationarity

through deferencing $\frac{\delta y}{\delta x}$ because the above graph as depicted in Fig.D/2, D/3 and data of Table D4 shows trends confirming unit roots presence.

Below is the data graph of first differencing of variables to attain stationarity labeled below as Fig D/5 
Fig.D/5

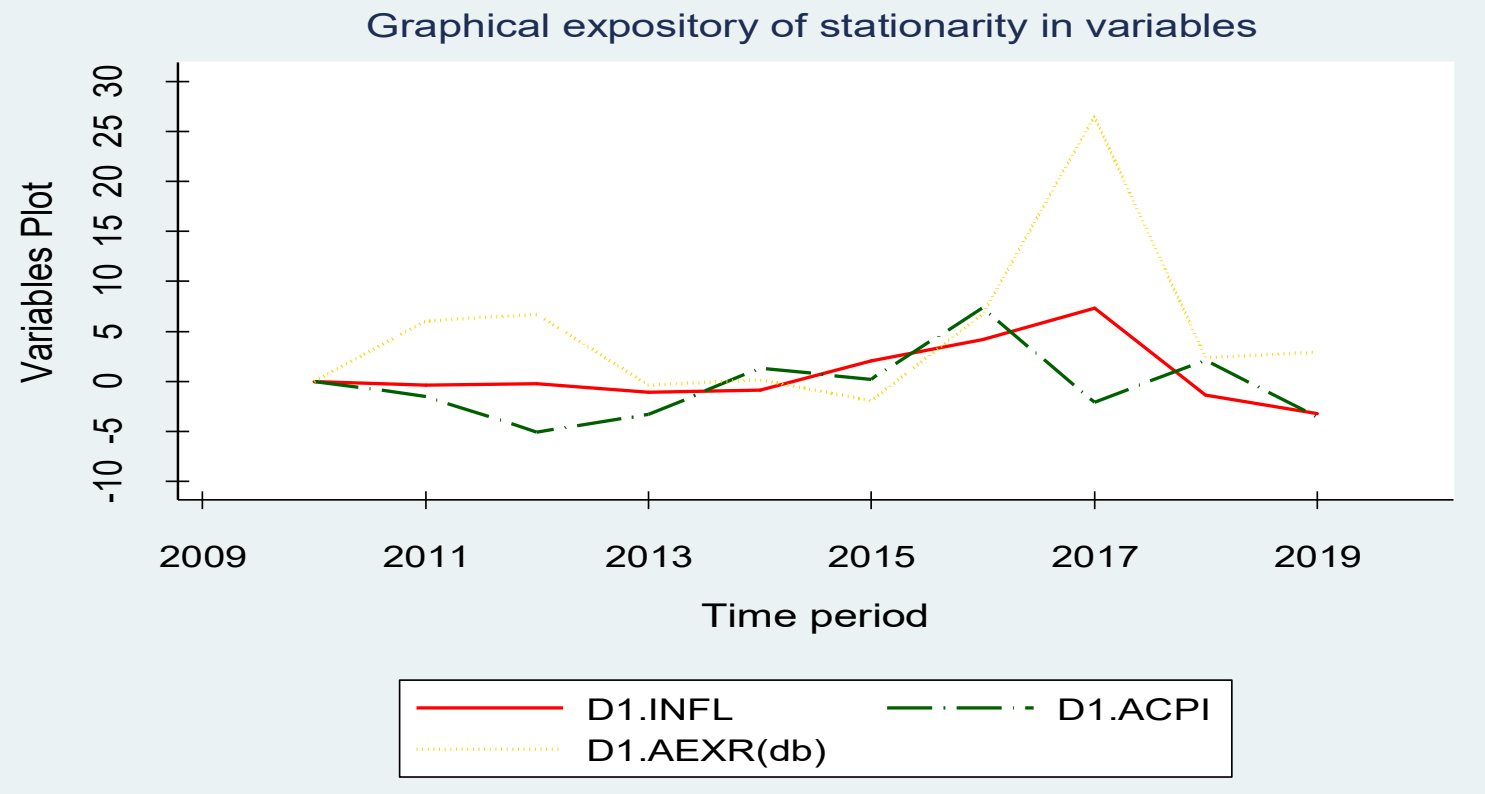

E. T. Senzu (2020)

After obtaining stationarity to the variables, which the researcher is depending on for analysis, various estimates and diagnostics checking were conducted using STATA 14 version with the observational reports outlined below under brief explanations.

I. First Observation report computed between $|\mathrm{D} 1 . \mathrm{AEXR}|$ and $|\mathrm{D} 1 . \mathrm{ACPI}|$;

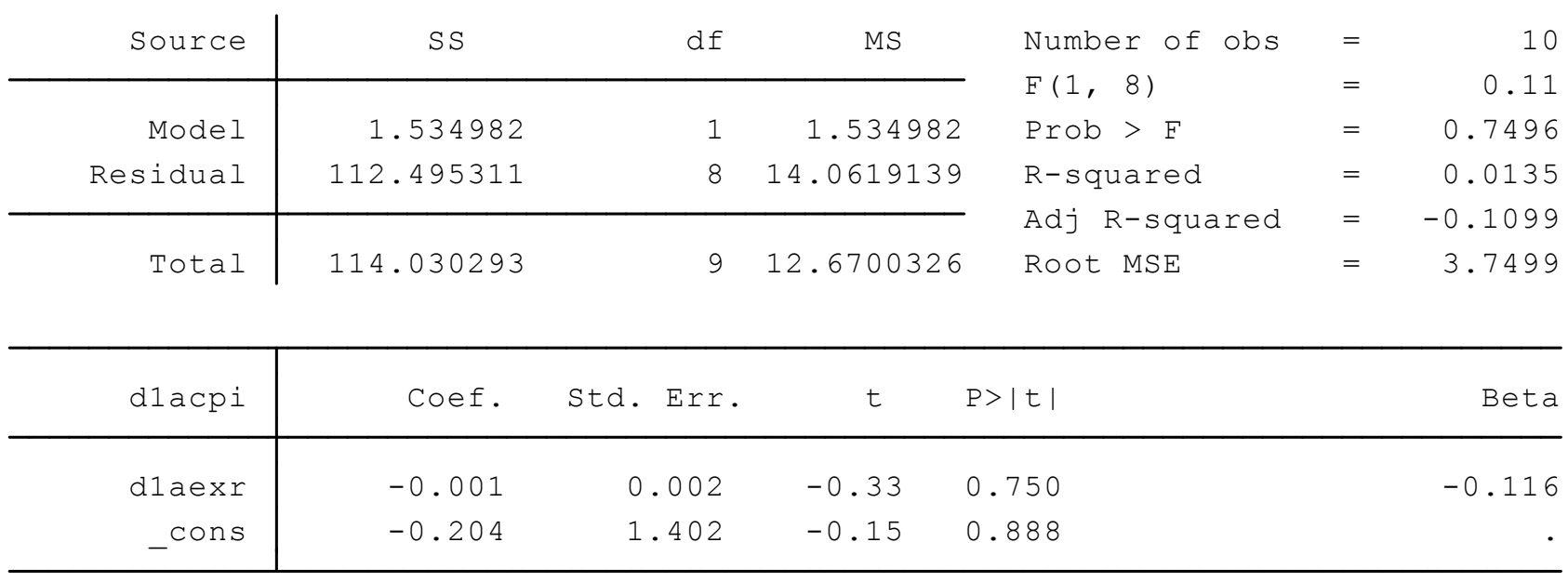


During the field study, we observed the likely collinearity between the open exchange rate market data collected on Leone currency and US dollar from a credible exchange rate company based in the UK, then collected Consumer price index data from Sierra Leone statistical services based in Freetown and subjected it into empirical diagnostic above. The findings suggest that there was the existence of correlation effect but minimal at a rate of 0.01 , however the low value of the standard error estimate at the range of $0.0-1.4$ is a strong signal of collinearity through its residual. Furthermore, the T-test at the range of -0.2 to -0.3 at a confidence interval of $95 \%$ confirms there was a significant similarity among the chosen variables. Finally, the high probability conditions $(0.75-0.89)$ of this findings was a piece of strong evidence to resolve the situation of collinearity status of the variables appreciating the vector direction of information flow among this two variables, hence resulted in depending on the exchange rate as the critical variable to rely upon to build the univariate model to estimate and forecast inflation in SLeconomy, elaborated above as Equation-3.

II. Second Observational report computed |D1.AINF| and |D1.AEXR|

\begin{tabular}{|c|c|c|c|c|c|c|}
\hline Source & SS & $d f$ & MS & Number of obs & $=$ & 10 \\
\hline Model & 48.3445639 & 1 & 48.3445639 & Prob > F & $=$ & 0.0124 \\
\hline Residual & 37.4856789 & 8 & 4.68570986 & R-squared & $=$ & 0.5633 \\
\hline Total & 85.8302428 & 9 & 9.53669364 & Root MSE & $=$ & 2.1647 \\
\hline dlinfl & Coef. & Std. Err. & t & $P>|t|$ & & Beta \\
\hline dlaexr & 0.003 & 0.001 & 3.212 & 0.012 & & 0.751 \\
\hline Cons & -0.744 & 0.810 & -0.919 & 0.385 & & • \\
\hline
\end{tabular}


From the empirical analysis, the coefficient of determination (R-square) was 0.6 suggesting a $60 \%$ quality of the regression model based on the exchange rate of sierra leone to predict its inflation rate. The Beta coefficient of the regression was 0.75 about $75 \%$ strong signal of the independent variable greater effect on the dependent variable. The observed standard deviation error of the regression was 0.001 , which is a signal of the independent variable quality to estimate the dependent variable. In respect to the diagnostics above, the auto-correlation of the regression model with first-degree freedom holds about $48.34 \%$ of the information in the prediction of the dependent variable, which is the inflation and the additional residual as the auto-correlation error model at the 8th degree of freedom, holds about $37.49 \%$ of information to predict the dependent variable. In the fusion of both structural models, the entire series is expected to hold about $85.83 \%$ of information reliable to the prediction of inflation in Sierra Leone economy with only $14.17 \%$ as non-accounted information within the structural challenges of the macroeconomy. Which suggest the quality nature of the model for inflation forecast of SLeconomy, which such equation model is outlined below as Eq.5

ARIMA $(1,1,8)$ : As a forecasting model equation, it holds the assumption that the data observation used for the model was contiguous. The model qualified as dynamic, relevant to Sierra Leone's economy at caeteris paribus.

$$
|I N F|_{t}=\left[\mu+\varepsilon_{t}+\beta_{1}|E X R|_{t}\right]+\left[\phi_{8} \sum_{i=(t-8)}^{n=8}|\varepsilon|+\varepsilon_{t}\right] \ldots \ldots E q .5
$$




\section{E. POLICY INSTRUMENT FRAMEWORK AS A THEORETICAL PROPOSITION}

Van Nispan (2011) defined policy instruments as a means of government intervention in market imperfections or, in a broader perspective, society in order to accomplish goals or to solve problems. And concluded, policy instrument comes not in isolation but is part of the intervention theory in tackling policy problems. The instrument becomes one of the variables in a contextual approach that takes policy implementation as a point of departure. Hood \& Halen (2007) made the first distinction between policy instrument, which considers one part of policy instrument for collection of information and classified as detectors and the second instruments directed to influence development in society classified as effectors. Which this paper hold-on to the latter, which is the effector's perspective.

Empirically, it became evident that inflation has a direct effect on the growth curve of Sierra Leone's economy. However, the policy to cap inflation rate or to allow it to operate in its natural trajectory is a decision of the Central Bank, which has its corresponding benefit and negative effect at the same time. The objective to maximize the degree of benefit against the negative effect of Inflation rate at the government level will depend on the appropriate policy instrument as a tool for economic growth. Empirically understanding that the major causal effect to inflation in the Sierra Leone economy is it open-market-exchange rate, which predicts over $85 \%$ of the inflation conditions within the macroeconomy, then under this heading, the paper seeks to establish a policy instrument as a framework to guide the Central Bank as the monetary institute and the Finance Ministry as the fiscal policy directorate of monetary affairs in conjunction with relevant stakeholders on behalf of the President to re-engineer the macroeconomic structural functioning for strong economic growth as the ultimate vision of a Welfare state. 


\section{INFLATION RATE POLICY INSTRUMENT FRAME WORK}




\begin{tabular}{|c|c|c|c|}
\hline Policy Instrument (Options) & $\begin{array}{l}\text { Seen Effects [ Both Short and } \\
\text { long term goals]: } \\
\text { Positive initiative for } \\
\text { macroeconomic growth }\end{array}$ & $\begin{array}{l}\text { Unseen effect [Short term } \\
\text { goals]: } \\
\text { Negative occurrence per } \\
\text { decisional effects }\end{array}$ & $\begin{array}{l}\text { Cautions and Conditions for } \\
\text { Policy effectiveness towards } \\
\text { sustainable macroeconomic } \\
\text { growth }\end{array}$ \\
\hline $\begin{array}{l}\text { Allow high exchange rate } \\
\text { against the leone currency }\end{array}$ & $\begin{array}{l}\text { 1. Develop a structured and } \\
\text { responsive [Chamber of } \\
\text { Commerce] for importation and } \\
\text { distribution. } \\
\text { 2. Initiate Exports promotion } \\
\text { programs for essential } \\
\text { production, which holds a } \\
\text { comparative advantage to the } \\
\text { Sierra Leone economy under a } \\
\text { structured Chamber of Industry } \\
\text { 3. Introduction of innovative } \\
\text { taxation program as a major } \\
\text { source of government revenue } \\
\text { with a controlled conditions as } \\
\text { a sub-policy program to avoid } \\
\text { uncontrolled consumer price at } \\
\text { the open-market. }\end{array}$ & $\begin{array}{l}\text { I. High inflation rate at a } \\
\text { controlled rate } \\
\text { II. A degree of a controlled } \\
\text { weak purchasing power of the } \\
\text { Leone currency }\end{array}$ & $\begin{array}{l}\text { 1. All the initiatives should be } \\
\text { monitored and coordinated by } \\
\text { government. } \\
\text { 2. The Chamber of Commerce } \\
\text { of import and the Industry } \\
\text { production of exports activities } \\
\text { should coordinate with the } \\
\text { proactive University faculties } \\
\text { as a mandate to support in the } \\
\text { intellectual framework and } \\
\text { labour forces of public-private } \\
\text { partnership and investment } \\
\text { initiatives lead by effective } \\
\text { private sector innovation and } \\
\text { efficient mechanism but } \\
\text { transparently regulated by } \\
\text { government operational system } \\
\text { as a welfare state. }\end{array}$ \\
\hline
\end{tabular}




\begin{tabular}{|c|c|c|c|}
\hline Striving for a low inflation rate & $\begin{array}{l}\text { 1. Initiative to cut-down } \\
\text { importation business to } \\
\text { "essential goods importation" } \\
\text { to support affected ventures as } \\
\text { a means to usher them into } \\
\text { exportation initiatives through } \\
\text { Export investment and } \\
\text { promotion programs with high } \\
\text { focus to the empowerment of a } \\
\text { Chamber of Industrial } \\
\text { initiatives for essential goods } \\
\text { production. } \\
\text { 2. Innovative tax initiative } \\
\text { programs for competitive } \\
\text { exportation ventures. } \\
\text { 3. Government should be } \\
\text { discipline to deficit spending } \\
\text { and set a cap on percentage of } \\
\text { excess deficit spending } \\
\text { annually, below } 3 \% \text { precisely } \\
\text { as a sub-policy program }\end{array}$ & $\begin{array}{l}\text { I. Low inflation rate } \\
\text { II. Strong purchasing power of } \\
\text { Leone currency and a quality } \\
\text { parity at the open exchange } \\
\text { market }\end{array}$ & $\begin{array}{l}\text { The ultimate focus of } \\
\text { government should be an } \\
\text { initiatives towards innovative } \\
\text { investment programs and } \\
\text { dynamic credit lending scheme } \\
\text { for private sector towards } \\
\text { production and exportation } \\
\text { drive as prescribed by Senzu } \\
\text { (2019/2020) on dynamic credit } \\
\text { lending effective to enterprises } \\
\text { in fragile economy }\end{array}$ \\
\hline
\end{tabular}




\section{F. FINDINGS AND CONCLUSIONS}

It became evident throughout the researcher study of Sierra Leone macro economy that the vector force underlying it economic growth decline or rise is largely inflation rate and the major predictive indicator to this inflation is it open-market- exchange rate of the Leone currency, such that any average shift of the leone price at the open market around +/- (0.032) to the USD in respect to the 10 years period spread sample data analysis, there is a percentage point shift of inflation effect. As a result, this paper proposes an alternative exchange rate policy instrument as a guide to the Central Bank and the government on decision choices to maximize economic benefit towards macroeconomic growth. 


\section{G. REFERNCES}

1. Andre Roncaglia, De., Ribeiro M. R. and Marques, M. A. (2017), “Economic development and inflation, a theoretical and empirical analysis." International review of applied economics.pp546-565. Vol.32, Issue 4. Taylor \& Francis Online.

2. Ashrat, Q., Gershman B., and Howitt, P. (2013), "How inflation affect macroeconomics performance".https://ideas.repec.org

3. Barro, R. J. (1995), “Inflation and economic growth.” Bank of England quarterly bulletin, May, 166-176.

4. Bastiat, C. F. (1801-1850), "Economic sophisms and, what is seen and what is not seen”.(eds)Jacques de Guenin(2016). Published by liberty fund, Inc.library of congress cataloging 16171819 p 654321 .

5. Beach D.(2017), “Qualitative political methodology.” Oxford Research Encyclopedias.

6. Bhatia, R. J. (1960), “Inflation, deflation, and economic development”. IMF staff papers 8(1), $101-144$.

7. Bruno, M. and Easterly, W. (1998), "Inflation crises and long-run growth". Journal of Monetary Economics. Vol.41, Issue 3-26. Elsevier.

8. DeGregorio, J. (1992), “The effect of inflation on economic growth.” European Economic Review $36(2-3), 417-424$.

9. DeGregorio J. (1993), "Inflation, taxation and long-run growth.” Journal of Monetary Economics. 31, 271-278. 
10. Dorrance, G. S. (1963), “The effect of inflation on economic development. IMF Staff papers 13(1), 82-102.

11. Dorrance, G. S. (1966), “Inflation and growth: the statistical evidence.” IMF Staff papers $10(1), 1-47$.

12. Evera, V. S. (2017), “Guide to methods for students of political science.” Published by Cornell University Press.

13. Fischer, S. (1993), “The role of macroeconomic factors in growth. Journal of Monetary Economics. 32(3), 485-511.

14. Galbis, V. (1979), "Money, investment and growth in Latin America 1961-1973." Economic development and cultural change 27(3), 423-443.

15. Hood, C.C. and Halen, M. Z. (2007), “The tools of government in a digital age.” Basingstoke: Palgrave.

16. Jackson, A., Tamuke, E., and Jabbie, M. (2019), “ Journal of Advanced Studies in Finance. Vol.10 No.2 pp.73-91. ISSN:2068-8393.

17. Gottschalk, J., Kalonji, K. and Miyajima, K.(2008), “Analyzing determinants of inflation, when there are data limitation: the case of Sierra Leone."https://www.imf.org

18. Johnson, H. G. (1967), "Is inflation a retarding factor in economic growth? In Krivine, D. (Ed.)fiscal and monetary problems in developing States. Praeger, New York. pp.121-137.

19. Kovanen, A.(2006), "Why do prices in Sierra Leone change so often? A case study using micro-level price data." IMF working paper 06/53 Washington. 
20. Levine, R. and Zervos, J. (1993), "What we have learned about policy and growth from cross-country regressions.” American Economic Review, paper and proceedings, 83, 426-430.

21. Pazos, F. (1972), “Chronic inflation in Latin America”. Praeger, New York.

22.Ravichandran, S. (2011), "Factors of persistent poverty in Sierra Leone. The University of Edinburg.UK. https://www.e-ir.info/2011/07/28/factors-of-persistent-poverty-in-sierra-leone/

23. Senzu, T. E (2019), “Theoretical perspective of dynamic credit risk analysis and lending models; effective to enterprises of a fragile economy." Published by Social Science Research Network. https://ssrn.com/abstract=3324909

24. Van Nispen, K. F(2011), "Policy instrument." Published by Robert Schuman Center of Advanced Studies, European University Institute.

25. Wai, U. T. (1959), "The relation between inflation and economic development; a statistical inductive study. IMF Staff papers 7(2), 302-317.

26. https://www.exchangerate.org.uk

27. https://www.statistics.s1

28. https://data.worldbank.org

29.https://www.imf.org/external/pubs/ft/wp/2008/wp08271.pdf 
